\title{
Poluição do Ar e Doenças Respiratórias: estudo de correlação das emissões atmosféricas e impacto nas cidades de Duque de Caxias (RJ) e Petrópolis (RJ) entre 2013 e 2017
}

\author{
Air Pollution and Respiratory Diseases: correlation study of atmospheric emissions \\ and impacts on the cities of Duque de Caxias (RJ) and Petrópolis (RJ) between 2013 \\ and 2017
}

Contaminación del Aire y Enfermedades Respiratorias: estudio de correlación de las emisiones atmosféricas e impactos en las ciudades de Duque de Caxias (RJ) y Petrópolis (RJ) entre 2013 y 2017

\author{
Antonio Carlos Oscar $\mathrm{Jr}^{1}$ \\ Juliana Loiola Rocha
}

\begin{abstract}
RESUMO: Duque de Caxias foi uma das cidades que teve seu crescimento associado às mudanças de espacialização das indústrias na Região Metropolitana do Rio de Janeiro (RMRJ) e nela, desde a década de 1960, está a Refinaria Duque de Caxias (REDUC), uma das três principais fontes poluidoras do estado. O objetivo desse estudo foi avaliar quantitativamente o impacto das emissões da REDUC na saúde da população de Duque de Caxias e Petrópolis. Foram trabalhados os dados dos anos de 2013 a 2017 sobre as emissões atmosféricas da estação de monitoramento da qualidade do ar próxima à REDUC, os dados meteorológicos do Pico do Couto e de internações por doenças do sistema respiratório. Para atingir o objetivo, foram realizadas correlações estatísticas por meio do teste de Spearman; já a Análise dos Componentes Principais (PCA) ajudou a compreender a variabilidade e as interações dos dados. Os resultados apontaram para a necessidade de maior preocupação com a emissão de partículas inaláveis. O teste não paramétrico indicou a maior correlação entre as partículas inaláveis e os casos de internação. O resultado do PCA também sugere que, em Petrópolis, as partículas inaláveis e o NO2, emitidos nas proximidades da REDUC, podem ter influência nas internações.
\end{abstract}

PALAVRAS-CHAVE: Clima urbano. Poluição atmosférica. Doenças respiratórias.

\begin{abstract}
Duque de Caxias was one of the cities that had its growth associated with changes in the spatialization of industries in the Metropolitan Region and in it, since the 60's, is the Duque de Caxias Refinery (REDUC), one of the 3 main polluting sources in the state. The objective of this study was to quantitatively evaluate the impact of REDUC emissions on the health of the population of Duque de Caxias and Petrópolis. Data from 2013 to 2017 were worked on atmospheric emissions from the air quality monitoring station near the refinery, Pico do Couto weather data and hospitalization for

\footnotetext{
1 Departamento de Geografia Universidade do Estado do Rio de Janeiro (DGF/IGEOG/UERJ). Rua São Francisco Xavier, 524, 40 andar, sala 4023, Bloco B, Maracanã, Rio de Janeiro / RJ - 20550-013. thony.oscar@gmail.com.

2 Departamento de Geografia Universidade do Estado do Rio de Janeiro (DGF/IGEOG/UERJ). Rua São Francisco Xavier, 524, 40 andar, sala 4023, Bloco B, Maracanã, Rio de Janeiro / RJ - 20550-013. julr27@hotmail.com.
} 
respiratory system diseases. To achieve the goal, statistical correlations were made through the Spearman test; On the other hand, Principal Component Analysis (PCA) helped to understand data variability and interactions. The results pointed to the need for greater concern with the emission of inhalable particles. The nonparametric test indicated a higher correlation between inhalable particles and hospitalization cases. The PCA result also suggests that in Petrópolis, Inhalable Particles and NO2, emitted by REDUC, may have an influence on hospitalizations.

KEYWORDS: Urban climate. Atmospheric pollution. Respiratory diseases.

RESUMEN: Duque de Caxias fue una de las ciudades que tuvo su crecimiento asociado con cambios en la espacialización de las industrias en la Región Metropolitana y en ella, desde los años 60, se encuentra la Refinería Duque de Caxias (REDUC), una de las 3 principales fuentes contaminantes en el estado. El objetivo de este estudio fue evaluar cuantitativamente el impacto de las emisiones de REDUC en la salud de la población de Duque de Caxias y Petrópolis. Los datos de 2013 a 2017 se trabajaron sobre las emisiones atmosféricas de la estación de monitoreo de la calidad del aire cerca de la refinería, los datos climáticos de Pico do Couto y la hospitalización por enfermedades del sistema respiratorio. Para lograr el objetivo, se realizaron correlaciones a través de la prueba de Spearman; Por otro lado, el Análisis de Componentes Principales (PCA) ayudó a comprender la variabilidad e interacciones de los datos. Los resultados señalaron la necesidad de una mayor preocupación con la emisión de partículas inhalables. La prueba no paramétrica indicó una mayor correlación entre las partículas inhalables y los casos de hospitalización. El resultado de PCA también sugiere que en Petrópolis, las partículas inhalables y el NO2, emitidos por REDUC, pueden influir en las hospitalizaciones.

PALABRAS-CLAVE: Clima urbano. Contaminación atmosférica. Enfermedades respiratorias.

\section{INTRODUÇÃO}

A poluição atmosférica é um tema de extrema importância, seja por sua repercussão econômica ou na saúde humana e, por isso, cada vez mais estudada, sobretudo nos países de industrialização recente (SALDIVA, 2018). Quando adentramos o ambiente urbano, no que se refere ao clima urbano, dada a complexidade deste ambiente, são diversas as fontes de emissão, tendo como destaque os veículos automotores (fontes móveis) e as indústrias (fontes fixas), sendo as fontes móveis as maiores responsáveis pela emissão de poluentes (FARIAS, 2013; GREGÓRIO, 2011).

Dado o modelo de crescimento econômico e ordenamento territorial implementado no Brasil (MELO, 2016) criaram-se alguns locais onde a poluição do ar é um dos principais problemas ambientais; talvez o grande símbolo brasileiro seja Cubatão - SP. No caso fluminense, o município de Duque de Caxias, que faz parte da Região Metropolitana do Rio de Janeiro (RMRJ), pode ser outro exemplo, uma vez que seu crescimento se deu pela migração de indústrias que buscavam solo urbano mais barato que os de bairros próximos da região central do Rio de Janeiro (DAVIDOVICH, 2010). Além disso, a implementação de 
ferrovias e rodovias que ligavam os dois municípios foram essenciais para que houvesse essa expansão, fazendo surgir condições para uma industrialização de alto impacto nesta periferia.

Duque de Caxias é hoje uma das cidades com alto grau de industrialização, e entre as empresas lá fixadas está a Petrobrás, em atividade desde 1960 com a Refinaria Duque de Caxias (REDUC), situada às margens de uma das grandes rodovias que cortam a cidade (BR040). No relatório anual de qualidade do ar de 2016 do (INEA), tendo como base o ano de 2015, a REDUC aparece como uma das três principais indústrias poluidoras do estado, junto com a Companhia Siderúrgica Nacional e a Thyssen Krupp Companhia Siderúrgica do Atlântico (INSTITUTO ESTADUAL DO AMBIENTE, 2016). De acordo com as palavras de Monteiro (1976, p. 49),

Nas concentrações urbanas, graças à circulação de veículos a autocombustão, à concentração industrial e outras formas de produção que contaminam a atmosfera. Aquela porcentagem insignificante de gases e impurezas na massa dos componentes básicos do ar, que se manifestava com relativa constância na face da Terra, vê-se acentuada a ponto de tornase perniciosa. Além disso, é uma carga que, partindo de certos pontos da cidade, difunde-se dentro dela e tende a ser exportada para o ambiente circundante.

Considerando o vento como fator de grande importância para a dispersão desses componentes é preciso compreender a topografia local e as interferências humanas. Farias (2013) explica que para entender a circulação atmosférica da planície ocupada pela Região Metropolitana do Rio de Janeiro (RMRJ) é preciso atentar para o fato de que a região é cercada pela Serra do Mar e possui três grandes maciços litorâneos: da Tijuca, da Pedra Branca e do Gericinó-Mendanha. O autor acrescenta que:

A topografia da RMRJ impõe resistência ao escoamento atmosférico, reduz a velocidade do vento e impede que a brisa marítima alcance determinados pontos do interior do continente, contribuindo para a estagnação de poluentes em alguns bairros e municípios (FARIAS, 2013, p. 49).

Levando em consideração que a área onde se encontra a REDUC (Figura 1) conta não só com a poluição da refinaria, como também com as indústrias subsidiárias (OSCAR JúNIOR, 2016) e o alto fluxo de carros da BR-040, e a poluição gerada pelo homem se difunde do local para áreas do entorno.

Gregório (2011), em sua dissertação de mestrado, fez uma análise complementar de risco utilizando simulações para a trajetória de poluentes a partir de empreendimentos altamente poluidores no Estado do Rio de Janeiro, verificando quais regiões poderiam ser mais afetadas. As simulações foram realizadas por meio do modelo de trajetórias cinemáticas desenvolvido por Freitas et al. (2004). Segundo Gregório (2011, p. 123): 
Esse modelo utiliza as análises que são geradas pelo modelo RAMS, apenas as variáveis referentes ao campo de vento ( $u, v$ e w). O RAMS (Regional Modeling System) é um modelo de simulação atmosférica, onde por meio dos dados meteorológicos do NCEP (National Centers for Environmental Prediction) simula o comportamento dos ventos, brisas na área de estudo.

Figura 1 - Contexto da área de estudo

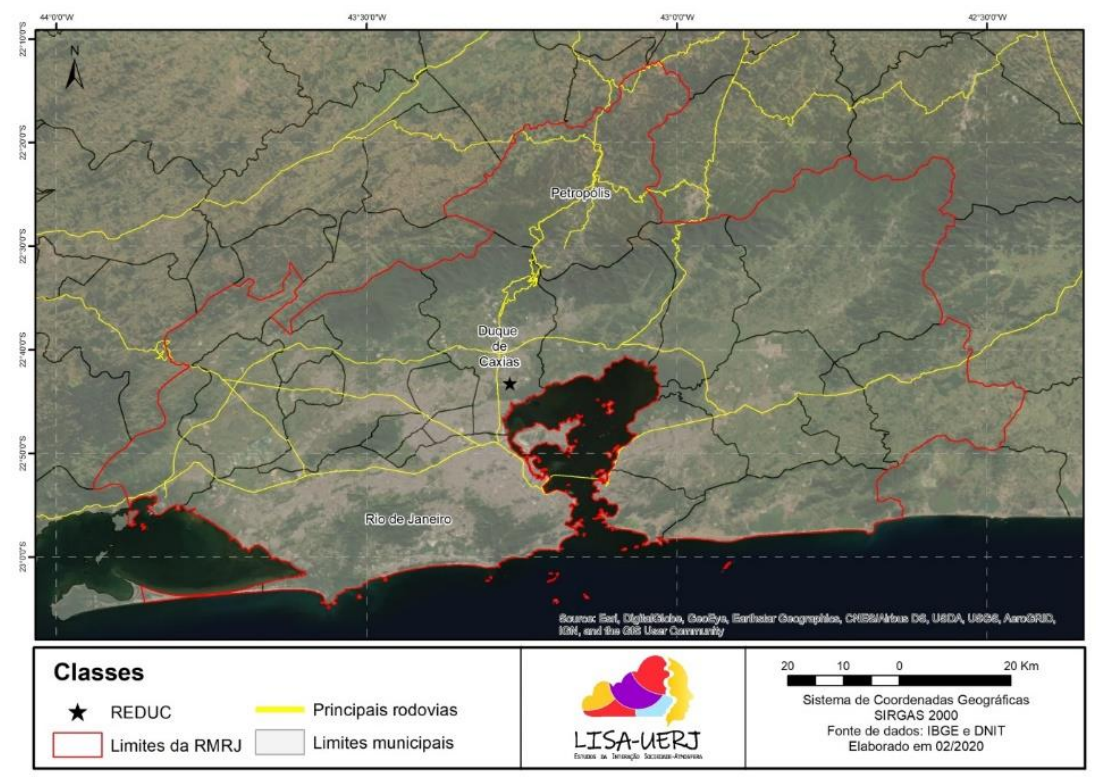

Fonte: elaboração dos autores, 2020.

Dentre as trajetórias elaboradas, uma foi feita com os poluentes provenientes da REDUC no dia 27 de agosto de 2007. No período da manhã foi constatado que os poluentes alcançaram 200 quilômetros de distância da REDUC, chegando à Região Norte do Estado do Rio de Janeiro. Porém, são os resultados da parte da tarde que chamaram a atenção para esse trabalho. Levando em consideração os seguintes aspectos meteorológicos:

Às 14 horas, a circulação se inverte, passando na parte sul a circularem de sul e sudeste para norte e noroeste e na parte norte, circulam de noroeste para nordeste. Este comportamento demonstra a atuação predominante do anticiclone do atlântico sul na região e, principalmente, no período da tarde, a atuação das brisas marítimas (GREGORIO, 2011, p. 124).

O resultado apresentado pelo modelo mostrou que as emissões atmosféricas da REDUC, devido a dinâmica de escoamento da atmosfera, conseguem ultrapassar a barreira natural da Serra do Mar e chegar até o Estado de Minas Gerais, passando pelo município de Petrópolis em cerca de 0,8 quilômetros de altitude. Dessa forma, os resultados da modelagem indicaram a possibilidade dos poluentes emitidos em um ente da federação afetar outro ente, mesmo em condição geográfica, a priori, desfavorável. 
Esse problema é mais uma das facetas do modelo urbano desenvolvido no Brasil, em que o processo de ordenamento territorial, ao desconsiderar o risco como elemento estruturante do território (EGLER, 1996) e se sujeitar às lógicas mercadológicas, contribui para uma maior exposição da população às mais diversas tipologias de risco (MELO 2016; OSCAR JÚNIOR, 2016). Esse quadro é agravado ainda pela dificuldade brasileira no trato regional, mesmo com as questões ambientais, o que favorece a intensificação da sociedade do risco defendida por Beck (2010), em que os riscos são produzidos pontualmente e distribuídos contiguamente.

Quanto ao risco, trata-se de uma categoria analítica associada às noções de incerteza; possibilidades de perdas e prejuízos sejam materiais, econômicos e/ou humanos em função de processos de ordem natural, social ou tecnológica. Entre outros, para Nunes (2009), o risco é a probabilidade de consequências danosas a partir da interação entre um evento deflagrador e as condições de vulnerabilidade da população. O grau de risco é mutável de acordo com o tempo e espaço e pode ser reduzido (mas nunca eliminado) através de ações que permitam às pessoas e instituições estarem preparadas para responder efetivamente aos efeitos danosos.

Portanto, considerando que tanto a análise do risco quanto a modelagem dão suporte ao prognóstico a partir de possibilidades e não da realidade (MELO, 2016), o presente estudo buscou correlacionar as emissões da REDUC, localizada em Duque de Caxias, com internações por doenças respiratórias nos municípios de Duque de Caxias e Petrópolis, entre os anos de 2013 e 2017. O objetivo é avaliar quantitativamente esse impacto, sobretudo em Petrópolis, oferecendo mais elementos para compreender a distribuição geográfica dos impactos das emissões de fontes fixas na saúde humana.

É importante ressaltar que os dados de emissão de poluentes são apenas da estação automática de monitoramento da qualidade do ar de Campos Elíseos, localizada na cidade de Duque de Caxias. Isso se deve ao fato de a cidade de Petrópolis possuir apenas uma estação meteorológica do Instituto Nacional de Meteorologia (INMET), a Pico do Couto, a qual não coleta dados sobre poluentes.

Estudos sobre a quantidade e concentração de poluentes são essenciais para problemas não só climáticos como também de saúde. De acordo com a Organização Mundial da Saúde (2005) de 20\% a 30\% de todas as doenças respiratórias podem ser relacionadas à poluição atmosférica. No Brasil, foi a partir de conferências, reuniões e encontros internacionais, como a Conferência de Estocolmo (1972), que as políticas para controle da qualidade do ar foram adotadas. Como resultado, em 1990 é criada a Resolução de № 3 pelo Conselho Nacional do Meio Ambiente (CONAMA), na qual se propões um padrão nacional de qualidade do ar com valores estipulados para cada tipo de poluente, referência neste estudo. 


\section{PRODUÇÃO DO ESPAÇO URBANO DA REGIÃO METROPOLITANA DO RIO DE JANEIRO E AS INDÚSTRIAS}

Segundo Abreu (1987), a expansão do espaço urbano da atual RMRJ tem sua história diretamente ligada aos meios de transporte e às indústrias. A construção da primeira ferrovia da cidade permitiu sua expansão para além do centro, já a criação dos bondes fez com que no século $X X$ fosse criada uma nova relação na cidade: trens para os pobres e bondes para os ricos que começam a se alocar na zona sul e em alguns bairros da zona norte mais próximos ao centro. As mudanças na cidade, junto com as mudanças na geopolítica internacional, resultaram em diversas mudanças no espaço metropolitano a partir do século XIX.

Ainda de acordo com Abreu (1987), ao iniciar o processo mais pesado de industrialização na cidade, na metade do século XIX, as pequenas lojas manufatureiras do centro da cidade passaram a se alocar em grandes casarões que um dia pertenceram à elite política e econômica local, que naquele momento começava a se deslocar para a zona sul da cidade. O primeiro bairro que se tornou referência para a indústria mais mecanizada foi São Cristóvão, que ao mesmo tempo que mantinha a proximidade com o centro, maior ponto de comercialização, mantinha-se também próximo aos principais pontos de meio de transporte, como a estrada de ferro Central do Brasil e, posteriormente, o porto, fundado no início do século seguinte.

Abreu (1987, p. 57) também destaca "[...] a existência de diversas fábricas na Baixada Fluminense, próximas às quedas d'água da Serra do Mar (em Pau Grande e na subida da Serra de Petrópolis), para aí atraídas pela oportunidade de geração de energia elétrica", sinalizando para o processo de instalação de indústrias pesadas e com alto potencial poluidor na periferia metropolitana mesmo antes da formação dos distritos que conhecemos hoje como as cidades de Duque de Caxias e São João de Meriti. Isso é importante para salientar que, para além do baixo valor do solo urbano, existiam recursos na Baixada Fluminense que atendiam às necessidades industriais.

O início do século XX foi marcado pelo pós-guerra e uma nova organização do espaço, que se deu de forma a alocar essas indústrias ainda mais distantes da área nobre que se delineava na formação territorial carioca. Segundo Abreu (1987), os trens estimularam esse primeiro grande fluxo para o subúrbio e a periferia, que por sua vez geraram acesso à mão de obra em maior quantidade e mais barata, além de lotes de terra mais baratos do que em outros bairros em que as indústrias se fixaram, como São Cristóvão. Assim, foram escolhidos como locais ideais para a implementação de parques industriais os bairros mais afastados da Zona Oeste e os municípios da Baixada Fluminense, limítrofes a metrópole. 
Dentre tantas mudanças urbanas na cidade, Marafon (2005, p. 31) ressalta que "[...] na segunda metade do século $X X$, seria a vez da malha viária rodoviária, que viria a atender a produção automobilística, de garantir a ampliação ainda maior da malha urbana". Nesse mesmo período foram construídos grandes eixos de acesso ao Rio de Janeiro, como a Rodovia Washington Luiz, nome do trecho da BR-040 que liga a cidade do Rio de Janeiro a Petrópolis, inaugurada em 1928. Em 1961 consolida-se a REDUC, que hoje, de acordo com informação do site da refinaria (PETROBRAS, 2020), é uma das maiores do Brasil no refinamento de petróleo, tendo como principais produtos óleo diesel, gasolina, querosene de aviação (QAV) e asfalto, todos capazes de gerar direta ou indiretamente gases poluentes altamente tóxicos ao homem.

A implementação de diferentes tipos de meio de transporte ao longo do século XX permitiu o crescimento industrial da periferia, já que facilitaram a chegada de mercadorias na cidade do Rio de Janeiro. Atualmente, observa-se a preponderância espacial de indústrias no território duquecaxiense, entre a REDUC e as grandes vias de circulação: Rodovia Washington Luiz (BR040), Avenida Governador Leonel de Moura Brizola (antiga RioPetrópolis/Presidente Kennedy), estrada FABOR, estada Rio D'ouro, estrada Automóvel Clube, BR116 (Rio-Magé) e, mais recentemente, o Arco Metropolitano e a Transbaixada (ainda em construção).

Seguindo a BR-040 e subindo a Serra do Mar, encontra-se Petrópolis. Segundo Cabral e Lopes (2016), Petrópolis, cuja fundação está diretamente ligada ao Imperador D. Pedro I, iniciou seu processo de industrialização junto com a cidade do Rio de Janeiro, ainda na década de 1870, com o setor têxtil merecedor de destaque, o que transformou a cidade em um polo de moda.

Em 1966, já existiam relatos tratados por Cabral e Lopes (2016) de como a saturação das indústrias em Petrópolis se tornaram um problema de infraestrutura, já que o crescimento dos investimentos na cidade não acompanhou o crescimento das indústrias, causando, por exemplo, a falta d'água para a produção. Além disso, é retratada a impossibilidade de concorrer com os produtos chineses que na década de 1960 já chegavam ao Brasil e os efeitos, que ainda podiam ser sentidos da crise de 1929. Com isso, na década de 1970 ganha força o processo de desindustrialização. Na bibliografia, o último dado para a distribuição por tipo de indústria em Petrópolis é tratado por Marafon (2005, p. 34), que trabalha com base em dados da antiga Fundação Centro de Informações e Dados do Rio de Janeiro (CIDE) e apresenta que:

O setor tem na indústria de transformação a sua maior contribuição. Cerca de $24,0 \%$ do total do valor da produção provém da indústria de máquinas e equipamentos, $19,0 \%$ da indústria de equipamentos e materiais médicos, 
$18,0 \%$ da indústria têxtil e do vestuário, $7,0 \%$ da indústria de bebidas, $7,0 \%$ da indústria de produtos alimentares e $7,0 \%$ da metalurgia.

A partir dessa reconstrução da produção do espaço da RMRJ, com ênfase nos municípios de Duque de Caxias e Petrópolis, é possível destacar elementos e atores do processo da organização e ordenamento do território que refletem diretamente a problemática dos riscos, sobretudo no que se refere às emissões atmosféricas e sua relação com os usos do solo e impactos na saúde humana. A seguir, fundamentando-se em dados observados e análises estatísticas demonstrar-se-á a relação entre eles.

\section{MATERIAIS E MÉTODOS}

Para a consecução dos objetivos da pesquisa foram obtidos dados junto ao (INEA) sobre a qualidade do ar da estação automática de qualidade do ar de Campos Elíseos, localizada na cidade de Duque de Caxias. Dentre os dados disponíveis no (INEA), foram trabalhados cinco poluentes dentro do padrão nacional apresentado na Resolução CONOMA de n. 3/1990, Brasil (1990): partículas inaláveis, dióxido de enxofre, monóxido de carbono, ozônio e dióxido de nitrogênio, detalhados no Quadro 1.

Quadro 1 - Efeito dos poluentes na saúde humana

\begin{tabular}{|l|l|}
\hline \multicolumn{1}{|c|}{ Poluentes } & \multicolumn{1}{c|}{ Efeitos na saúde humana } \\
\hline $\begin{array}{l}\text { Monóxido de } \\
\text { Carbono }(\mathrm{CO})\end{array}$ & $\begin{array}{l}\text { Alta afinidade pela hemoglobina, formação de carboxihemoglobina, efeitos } \\
\text { clínicos cardiovasculares e comportamentais. }\end{array}$ \\
\hline $\begin{array}{l}\text { Partículas } \\
\text { inaláveis }(\mathrm{PI})\end{array}$ & $\begin{array}{l}\text { Causam alergias, asma e bronquite crônica, além de irritação nos olhos e } \\
\text { garganta, reduzindo a resistência às infecções. }\end{array}$ \\
\hline $\begin{array}{l}\text { Dióxido de } \\
\text { Enxofre }\left(\mathrm{SO}_{2}\right)\end{array}$ & $\begin{array}{l}\text { Ação irritante nos canais respiratórios, provocando tosse, agravando a asma e a } \\
\text { bronquite crônica e atingindo outros órgãos. }\end{array}$ \\
\hline Ozônio $\left(\mathrm{O}_{3}\right)$ & $\begin{array}{l}\text { Altamente tóxico. Provoca irritação nos olhos, nariz e garganta, envelhecimento } \\
\text { precoce da pele, náusea, dor de cabeça, tosse, fadiga, aumento do muco, } \\
\text { diminuição da resistência orgânica às infecções e agravamento de doenças } \\
\text { respiratórias. }\end{array}$ \\
\hline $\begin{array}{l}\text { Dióxido de } \\
\text { Nitrogênio } \\
\left(\mathrm{SO}_{2}\right)\end{array}$ & Irrita os olhos e o nariz, além de provocar enfisema pulmonar. \\
\hline
\end{tabular}

Fonte: adaptado de Brasil (2018).

Todos os poluentes supracitados foram analisados de acordo com os padrões estabelecidos pela resolução acima citada, considerando a concentração de cada poluente em um determinado tempo de exposição pré-estabelecido. Assim, de acordo com os parâmetros nacionais, as partículas inaláveis e o dióxido de enxofre foram analisados a cada 24 horas e pela média aritmética anual (MAA); o monóxido de carbono foi analisado de hora em hora, também, a cada 8 horas; o ozônio foi analisado apenas a cada hora; e o dióxido de nitrogênio foi analisado a cada hora e pela (MAA). 
Vale ressaltar que os dados obtidos junto ao (INEA) foram disponibilizados em unidades de concentração diferentes da referência nacional apresentada pelas resoluções do CONAMA (BRASIL, 1990). Para tanto, foi necessário realizar a conversão de unidades, sendo as mesmas feitas por meio do site (ENDMEMO, 2020) que considera $1 \mathrm{mg} / \mathrm{m} 3$ equivalente a 0.001 ppm e a 1 ppb.

Em um segundo momento foi necessário obter os dados de internações por doenças do aparelho respiratório. No site do Departamento de Informática do SUS foi possível obter os dados consolidados por local de internação a partir de 2008 (DATASUS, 2018). Dessa forma foram coletados os dados para o Estado do Rio de Janeiro, para a RMRJ e também para os municípios de Duque de Caxias e Petrópolis. Tais dados apresentam-se agregados, ou seja, não sendo possível seu detalhamento por unidade pública de saúde.

O terceiro passo consistiu em obter os dados sobre pluviosidade, velocidade e direção do vento da estação automática de Pico do Couto (Petrópolis) pelo site do INMET. Os dados de pluviosidade foram classificados segundo a proposta de Galvani e Luchiari (2005, p. 5701), considerando "[...] os limites numéricos daqueles anos considerados com regime pluviométrico normal, seco ou úmido, além daqueles considerados super úmidos e super secos". Para tanto, foram definidos para cada mês o valor mínimo, o valor máximo, a mediana, o primeiro quartil e o segundo quartil.

O quarto momento consistiu em fazer testes estatísticos com os dados através do software Statistica (versão 10) em que as emissões máximas em 24 horas foram correlacionadas com os dados de internação do mês subsequente, considerando, portanto, um tempo de recorrência (lag), já que as manifestações clínicas e internações não ocorrem imediatamente após a exposição do indivíduo. O teste não paramétrico de Spearman foi utilizado para traçar uma correlação entre as internações e os poluentes.

Já a técnica dos componentes principais (PCA, sigla em inglês) possibilitou a análise multivariada dos dados. Ela foi aplicada para extrair relações/padrões espaciais entre as amostras e os poluentes. Conforme Lyra et al. (2010, p. 1594), a PCA pode "[...] revelar a existência ou não de amostras anômalas, de relações entre as variáveis medidas e de relações ou agrupamentos entre amostras".

\section{RESULTADOS}

Ao comparar os valores estabelecidos pela Resolução CONAMA n.ำ 3/1990, Brasil (1990) e os valores monitorados pelo (INEA) entre os anos de 2013 e 2017, o único poluente que possui valores dentro dos padrões primário e secundário são as partículas inaláveis, ou seja, todos os demais poluentes excederam os parâmetros nacionais, significando impactos na qualidade ambiental e na maior exposição da população a doenças. 
Dando ênfase às partículas inaláveis que chamam a atenção por ser o poluente mais regular, percebe-se que os anos de 2014 e 2015 foram os que tiveram mais dias dentro dos padrões primário e secundário (superior a 200 dias); além do mais, em três dos cinco anos trabalhados, a (MAA) também estava dentro dos padrões. Vale, contudo, frisar que para o ano de 2017 faltam muitos dados nos meses de maio e junho, os quais aparecem com uma expressiva quantidade de dias com alta emissão nos outros anos. Considerando ainda os níveis de atenção, alerta e emergência divulgados pelo Instituto Estadual do Ambiente (INEA), o ano de 2017 foi marcado por altos níveis de poluição, totalizando: 10 dias em estágio de atenção e três dias em estágio de alerta, sendo que um deles quase alcançou o estado de emergência, ratificando a hipótese de que essas falhas nos dados mascararam os resultados.

Antes de realizar as análises estatísticas, foram estudados dois parâmetros meteorológicos: a pluviosidade e os ventos. Estas variáveis ajudam a compreender melhor as condições de tempo durante o período analisado e o comportamento de dispersão dos poluentes.

$\mathrm{Na}$ Tabela 1 apresenta-se a classificação dos meses chuvosos de acordo com Galvani e Luchiari (2005). Nela pode-se constatar que o ano mais chuvoso foi 2013, já o mais seco foi 2017. Esses resultados relacionam-se com os dados de poluição do ar, já que há uma recorrência de violação dos padrões de qualidade do ar nos meses e anos mais secos, um resultado da maior permanência de tais poluentes na atmosfera. Para o ano de 2017, tratado anteriormente, o mês de junho se destaca pelas maiores taxas de emissão atmosférica e, não concidentemente, ser classificado como um mês super seco.

Tabela 1 - Classificação da pluviosidade mensal entre 2013 e 2017 para a estação Pico do Couto

\begin{tabular}{|c|c|c|c|c|c|c|c|c|c|c|c|c|}
\hline & \multicolumn{12}{|c|}{ Pluviosidade total $(\mathrm{mm})$} \\
\hline & JANEIRO & FEVEREIRO & MARÇO & ABRIL & MAIO & JUNHO & JULHO & AGOSTO & SETEMBRO & OUTUBRO & NOVEMBRO & DEZEMBRO \\
\hline 2013 & 501,6 & 158,8 & 479,4 & 146,0 & 132,8 & 62,8 & 126,0 & 39,8 & 104,2 & 130,8 & 319,0 & 319,8 \\
\hline 2014 & 122,0 & 64,0 & 229,0 & 219,4 & 62,0 & 72,6 & 72,8 & 82,6 & 64,0 & 149,8 & 226,4 & 220,2 \\
\hline 2015 & 7,8 & & & 4,2 & 84,4 & 108,0 & 22,0 & 29,6 & 110,8 & 54,4 & 26,4 & \\
\hline 2016 & & & & 13,0 & 45,4 & 101,0 & 7,2 & 66,0 & 32,6 & 0,4 & 7,4 & 324,8 \\
\hline 2017 & 255,0 & 312,0 & 204,2 & 179,4 & 41,8 & 42,2 & 73,0 & 31,2 & 5,8 & 32,2 & 243,2 & 197,0 \\
\hline
\end{tabular}

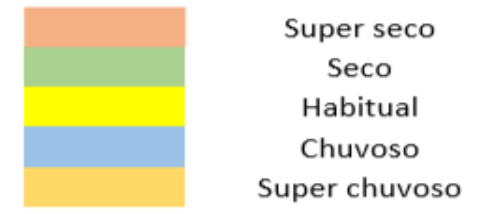

Fonte: elaboração dos autores, 2020.

Em relação ao vento, principal elemento de dispersão de poluentes na atmosfera, a Figura 2 apresenta o panorama dos ventos para o período de 2013 a 2017, e já a Figura 3 dá ênfase à situação dos ventos no inverno de 2017, estação do ano em que o impacto da 
poluição do ar é maior. Observam-se em ambas as figuras que o vento predominante é do quadrante noroeste. Esta configuração dos ventos, associada à topografia local e à predominância dos sistemas atmosféricos, ajudam no escoamento e dispersão dos poluentes no município de Petrópolis, o que não é observado em Duque de Caxias, conforme Oscar Júnior (2016). Apesar disso, conforme observado por Gregório (2011), existem situações sinóticas especificas que permitem o escoamento e deposição de poluentes em Petrópolis.

\section{Figura 2 - Rosa dos ventos para o período de 2013 a 2017 para a estação Pico do Couto}

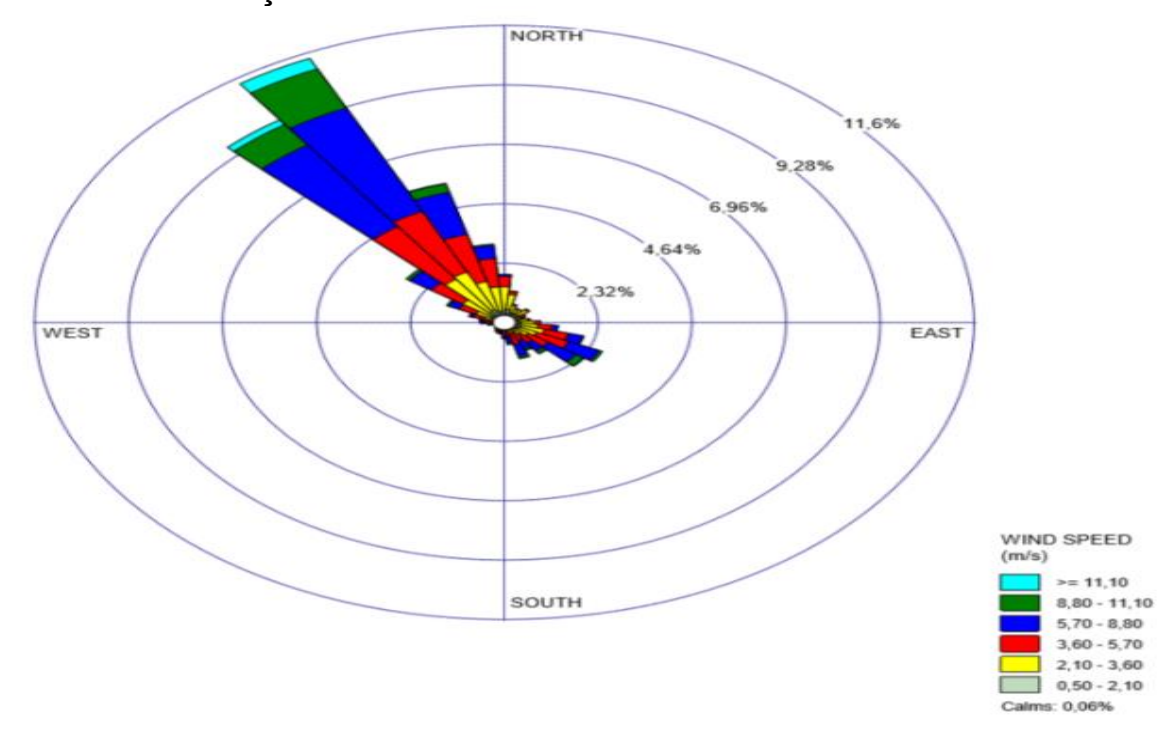

Fonte: elaboração dos autores, 2020.

Para os dados de poluentes, primeiramente foi aplicada a técnica do boxplot que segundo Galvani e Luchiari (2005, p. 5701) “[...] permite identificar [...] os valores máximos, os mínimos, a mediana, o primeiro quartil e o terceiro quartil". A partir dos resultados obtidos nas Figuras 4 e 5, conclui-se que através da irregularidade da forma da caixa e dos outliers a distribuição dos dados não segue a distribuição normal, informação fundamental para a adequada escolha das técnicas estatísticas a seguir.

Levando em consideração, portanto, a não normalidade apresentada nos dados, tanto as correlações quanto a análises de componentes principais foram feitas pelo método de Spearman. O resultado da correlação de Spearman, com nível de confiança de 95\% para Duque de Caxias, indica que o gás que tem a maior correlação com as internações são as partículas inaláveis $(23,7 \%)$, em seguida o monóxido de carbono $(10,5 \%)$ e o dióxido de nitrogênio $(7,2 \%)$. Já o ozônio e o enxofre possuem uma correlação negativa e pouco expressiva, conforme a Tabela 2.

Para Petrópolis (Tabela 3), assim como para Duque de Caxias, o poluente com maior correlação também foram as partículas inaláveis $(40,9 \%)$. O dióxido de nitrogênio $(9,8 \%)$ e o 
monóxido de carbono $(2,4 \%)$ apresentam uma baixa correlação, enquanto o dióxido de enxofre $(2,1 \%)$ e o ozônio (1,3\%) possuem uma correlação negativa igualmente baixa.

Figura 3 - Rosa dos ventos para o inverno de 2017 para a estação Pico do Couto

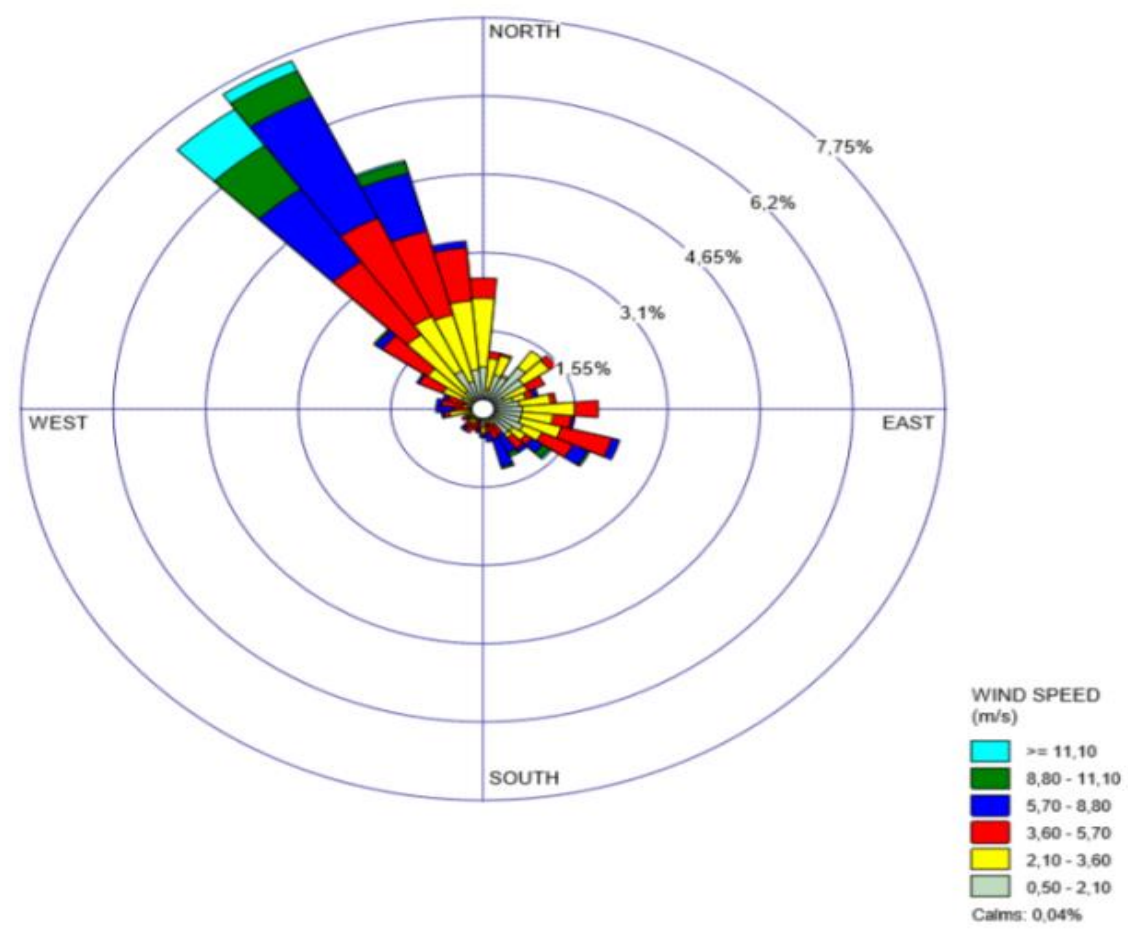

Fonte: elaboração dos autores, 2020.

Figura 4 - Exemplo de Boxplot, corresponde ao Monóxido de Carbono para Petrópolis (2017)

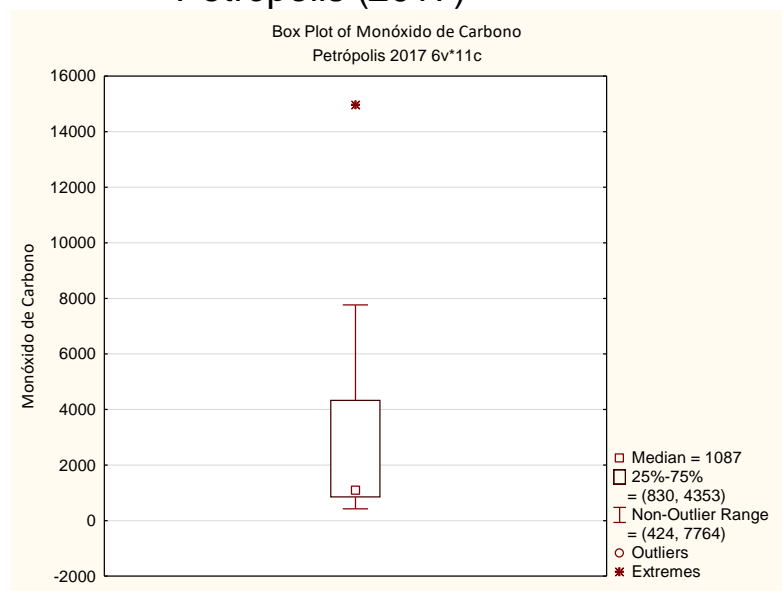

Fonte: elaboração dos autores, 2020.

A correlação negativa e pouco expressiva do dióxido de enxofre e ozônio (produtos importantes do refino de petróleo) com internações, tanto em Duque de Caxias quanto em Petrópolis, muito provavelmente deve-se às características destes gases. O primeiro devido a sua facilidade de reagir com outros compostos na atmosfera formando material particulado; 
já o ozônio por ser derivado de reações químicas complexas entre o dióxido de nitrogênio e os compostos orgânicos voláteis sob temperaturas elevadas. A associação entre esses gases está expressa estatisticamente nas Tabelas 2 e 3.

Figuras 5 - Exemplo de Boxplot, corresponde ao Ozônio para Caxias (2013)

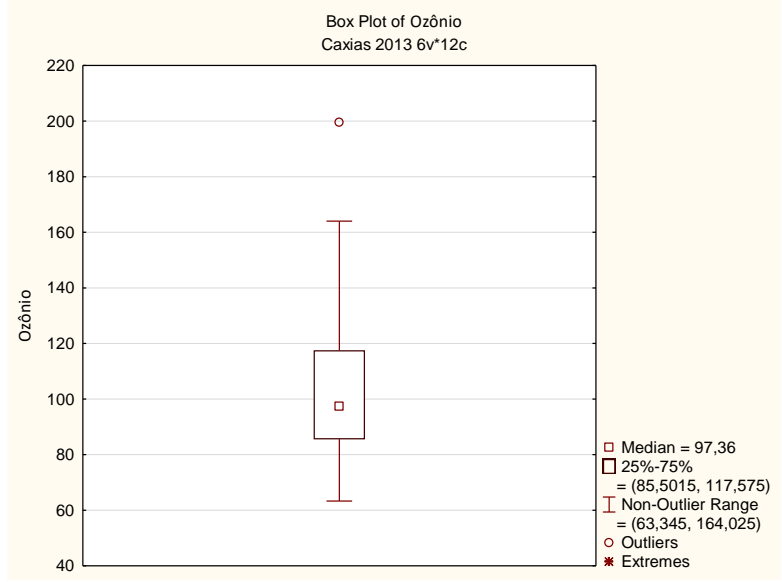

Fonte: elaboração dos autores, 2020.

Tabela 2 - Correlação de Spearman para Duque de Caxias entre os poluentes e internações. Destaques em vermelho para as correlações mais expressivas

\begin{tabular}{|c|c|c|c|c|c|c|}
\hline & Internações & Dióxido de Enxofre & Dióxido de Nitrogênio & Monóxido de Carbono & Ozônio & Particulas Inaláveis $(<10 \mu \mathrm{m})$ \\
\hline Internações & 1,000000 & $-0,032792$ & 0,072722 & 0,105535 & $-0,063654$ & 0,237232 \\
\hline Dióxido de Enxofre & $-0,032792$ & 1,000000 & $-0,077522$ & 0,004676 & 0,049269 & $-0,025921$ \\
\hline Dióxido de Nitrogênio & 0,072722 & $-0,077522$ & 1,000000 & 0,121048 & 0,351627 & 0,373878 \\
\hline Monóxido de Carbono & 0,105535 & 0,004676 & 0,121048 & 1,000000 & 0,087434 & 0,111077 \\
\hline Ozônio & $-0,063654$ & 0,049269 & 0,351627 & 0,087434 & 1,000000 & 0,090767 \\
\hline Partículas Inaláveis $(<10 \mu m)$ & 0,237232 & $-0,025921$ & 0,373878 & 0,111077 & 0,090767 & 1,000000 \\
\hline
\end{tabular}

Fonte: elaboração dos autores, 2020.

Tabela 3 - Correlação de Spearman para Petrópolis entre os poluentes e internações. Destaques em vermelho para as correlações mais expressivas

\begin{tabular}{|c|c|c|c|c|c|c|}
\hline & Internações & Dióxido de Enxofre & Dióxido de Nitrogênio & Monóxido de Carbono & Ozônio & Partículas Inaláveis $(<10 \mu \mathrm{m})$ \\
\hline Internações & 1,000000 & $-0,211929$ & 0,098424 & 0,024905 & $-0,013768$ & 0,408752 \\
\hline Dióxido de Enxofre & $-0,211929$ & 1,000000 & $-0,077522$ & 0,004676 & 0,049269 & $-0,025921$ \\
\hline Dióxido de Nitrogênio & 0,098424 & $-0,077522$ & 1,000000 & 0,121048 & 0,351627 & 0,373878 \\
\hline Monóxido de Carbono & 0,024905 & 0,004676 & 0,121048 & 1,000000 & 0,087434 & 0,111077 \\
\hline Ozônio & $-0,013768$ & 0,049269 & 0,351627 & 0,087434 & 1,000000 & 0,090767 \\
\hline Partículas Inaláveis $(<10 \mu \mathrm{m})$ & 0,408752 & $-0,025921$ & 0,373878 & 0,111077 & 0,090767 & 1,000000 \\
\hline
\end{tabular}

Fonte: elaboração dos autores, 2020.

A fim de complementar a análise estatística, utilizou-se como recurso a análise de componentes principais. Para Duque de Caxias a técnica indicou que quatro componentes são responsáveis por quase $80 \%$ da variância dos dados, conforme a Tabela 4 e a Figura 6 , esses quatro componentes reduzem e explicam todo o banco de dados.

Por meio da Figura 6, observa-se de forma mais clara o resultado da técnica. O gráfico abaixo mostra a variância para cada componente, chegando ao valor acumulado de 79,5\%, variância indicada para uma adequada representação amostral (LYRA et al., 2010). Conforme 
se observa, a primeira componente explica $26,2 \%$ da variância dos dados, a segunda $19,3 \%$, a terceira $17,1 \%$ e a quarta $16,8 \%$. Com isso, as duas primeiras componentes explicam a maior variância dos dados (45,55\%), demonstrando a importância de ambas, já que conjuntamente explicam quase que a metade da variância do conjunto de dados.

Tabela 4 - Sumário estatístico da PCA para os dados de Duque de Caxias

\begin{tabular}{|c|c|c|c|c|c|c|c|c|}
\hline \multirow[b]{2}{*}{ Component } & \multicolumn{8}{|c|}{$\begin{array}{l}\text { Principal Components Analysis Summary (Caxias) } \\
\text { Number of components is } 4 \\
79,5119 \% \text { of sum of squares has been explained by all the extracted components. }\end{array}$} \\
\hline & $\mathrm{R}^{2} \mathrm{X}$ & $\mathrm{R}^{2} \mathrm{X}$ (Cumul.) & Eigenvalues & $Q^{2}$ & Limit & $\mathrm{Q}^{2}$ (Cumul.) & Significance & Iterations \\
\hline 1 & 0,262404 & 0,262404 & 1,574423 & $-0,045104$ & 0,181034 & $-0,045104$ & $S$ & 17 \\
\hline 2 & 0,193111 & 0,455515 & 1,158669 & $-0,100000$ & 0,214035 & $-0,187962$ & UNKNOWN & 31 \\
\hline 3 & 0,171141 & 0,626656 & 1,026846 & $-0,100000$ & 0,263393 & $-0,382085$ & NS & 17 \\
\hline 4 & 0,168463 & 0,795119 & 1,010778 & 0,046377 & 0,345455 & $-0,317988$ & NS & 8 \\
\hline
\end{tabular}

Fonte: elaboração dos autores, 2020.

Figura 6 - Variância de cada componente principal para Duque de Caxias

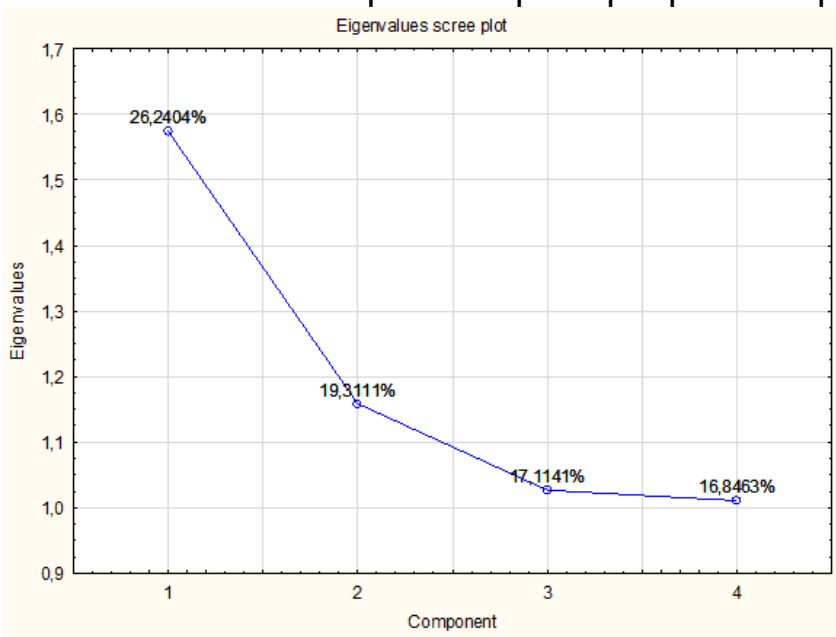

Fonte: elaboração dos autores, 2020.

O resultado a seguir (Tabela 5 ) ajuda a identificar os poluentes mais importantes e o tipo de relação existente com as internações; trata-se do resultado das cargas fatoriais obtidas a partir da técnica da PCA.

Tabela 5 - Carga dos poluentes em cada componente indicando os com maior força para Caxias. Os valores destacados em azul foram os mais expressivos

\begin{tabular}{l|r|r|r|r|r}
\hline \hline \multirow{2}{*}{ Variable } & \multicolumn{6}{l}{$\begin{array}{l}\text { Loading spreadsheet (Caxias) } \\
\text { Number of components is 4 }\end{array}$} \\
\cline { 2 - 6 } & $\begin{array}{c}\text { Variable } \\
\text { number }\end{array}$ & Component 1 & Component 2 & Component 3 & Component 4 \\
\hline Internações & 1 & 0,303798 & $-0,800833$ & 0,110249 & 0,120442 \\
\hline Dióxido de Enxofre & 2 & $-0,240096$ & 0,174908 & 0,911386 & $-0,119778$ \\
\hline Dióxido de Nitrogênio & 3 & 0,794894 & 0,192047 & $-0,154275$ & $-0,024041$ \\
\hline Monóxido de Carbono & 4 & $-0,030574$ & 0,374385 & 0,021742 & 0,905509 \\
\hline Ozônio & 5 & 0,642077 & 0,485440 & 0,112739 & $-0,292797$ \\
\hline Partículas Inaláveis $(<10 \mu \mathrm{m})$ & 6 & 0,615979 & $-0,272110$ & 0,383514 & 0,275082 \\
\hline \hline
\end{tabular}

Fonte: elaboração dos autores, 2020. 
Na Tabela 5 é possível observar que a componente 1 é mais bem explicada pelo dióxido de nitrogênio, com uma associação positiva com as internações; a componente 2 é explicada pela emissão de ozônio, porém, em associação é inversa com as internações. Conforme análise anterior, estes dois gases referem-se àqueles que melhor explicam a variância do conjunto de dados, ou seja, referem-se aos poluentes mais expressivos da estação de monitoramento de qualidade do ar da REDUC. Para as demais componentes, a 3 é explicada pela presença do dióxido de enxofre e possui uma associação positiva com as internações. Finalmente, a componente 4 é o monóxido de carbono, em que a associação com as internações é positiva.

A mesma análise foi realizada para Petrópolis, considerando os poluentes emitidos nas proximidades da REDUC e as internações em seu município. Neste caso, quatro componentes foram responsáveis por $82,30 \%$ da variância dos dados (Tabela 6).

Tabela 6 - Sumário estatístico da PCA para os dados de Petrópolis

\begin{tabular}{|c|c|c|c|c|c|c|c|c|}
\hline \multirow[b]{2}{*}{ Component } & \multicolumn{8}{|c|}{$\begin{array}{l}\text { Principal Components Analysis Summary (Spreadsheet5) } \\
\text { Number of components is } 4 \\
82,3015 \% \text { of sum of squares has been explained by all the extracted components. }\end{array}$} \\
\hline & $R^{2} X$ & $\mathrm{R}^{2} \mathrm{X}$ (Cumul.) & Eigenvalues & $Q^{2}$ & Limit & $\mathrm{Q}^{2}$ (Cumul.) & Significance & Iterations \\
\hline 1 & 0,280353 & 0,280353 & 1,682115 & $-0,038496$ & 0,181034 & $-0,038496$ & $S$ & 14 \\
\hline 2 & 0,204460 & 0,484812 & 1,226757 & $-0,067822$ & 0,214035 & $-0,108930$ & NS & 29 \\
\hline 3 & 0,170705 & & 1,024227 & $-0,10$ & 0,2 & & NS & 50 \\
\hline 4 & 0,167498 & 0,823015 & 1,004989 & 0,094109 & 0,345455 & $-0,147890$ & NS & 6 \\
\hline
\end{tabular}

Fonte: elaboração dos autores, 2020.

Para uma visualização mais clara dos dados, também foi gerado para Petrópolis o gráfico com a contribuição percentual de cada componente para a variância do conjunto de dados (Figura 7). Nesse caso, a primeira componente explica $28 \%$, a segunda $20,4 \%$, a terceira $17 \%$ e a quarta $16,7 \%$. Mais uma vez, as duas primeiras componentes somadas explicam quase $50 \%$ da variância dos dados.

Figura 7 - Variância dos componentes para Petrópolis

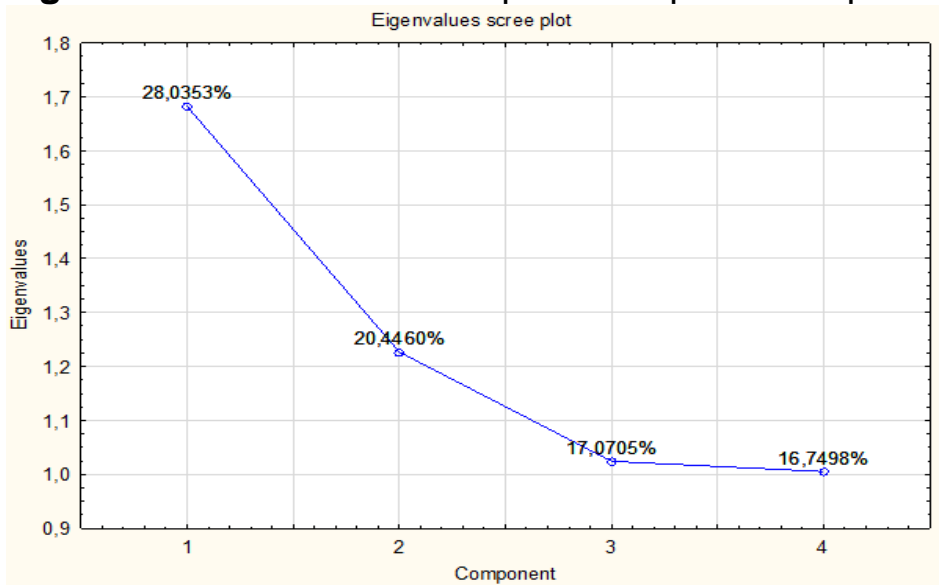

Fonte: elaboração dos autores, 2020. 
$\mathrm{Na}$ Tabela 7 encontram-se as cargas fatoriais para cada componente. No caso de Petrópolis, os poluentes que melhor explicam a primeira componente são as partículas inaláveis e o dióxido de nitrogênio, possuindo uma associação positiva com as internações. Já a segunda componente é explicada pela emissão de ozônio, neste caso em associação negativa com as internações. Para a terceira componente, o monóxido de carbono apresenta a maior carga fatorial, bem como uma associação positiva com as internações. Enfim, a quarta componente é explicada pelo dióxido de enxofre, também em associação positiva com as internações. Assim como em Duque de Caxias, o ozônio e o dióxido de nitrogênio são os gases que melhor explicam a variância do conjunto de dados, assumindo importância significativa entre os poluentes que afetam as internações; no entanto, para Petrópolis, as partículas inaláveis também têm significativa importância, afinal são as que melhor explicam a primeira componente principal para o município.

Tabela 7 - Carga dos poluentes em cada componente indicando os com maior força para Petrópolis. Os valores destacados em azul foram os mais expressivos

\begin{tabular}{l|r|r|r|r|r}
\hline \multirow{2}{*}{ Variable } & \multicolumn{7}{|l}{$\begin{array}{l}\text { Loading spreadsheet (Spreadsheet5) } \\
\text { Number of components is 4 }\end{array}$} \\
\cline { 2 - 7 } & $\begin{array}{l}\text { Variable } \\
\text { number }\end{array}$ & Component 1 & Component 2 & Component 3 & Component 4 \\
\hline Internações & 1 & 0,599163 & $-0,640509$ & 0,063216 & 0,113131 \\
\hline Dióxido de Enxofre & 2 & $-0,332916$ & 0,314733 & 0,368505 & 0,765489 \\
\hline Dióxido de Nitrogênio & 3 & 0,678886 & 0,447637 & $-0,105168$ & $-0,181410$ \\
\hline Monóxido de Carbono & 4 & $-0,045328$ & 0,174912 & 0,840674 & $-0,500589$ \\
\hline Ozônio & 5 & 0,503654 & 0,667078 & $-0,146714$ & 0,102709 \\
\hline Partículas Inaláveis $(<10 \mu \mathrm{m})$ & 6 & 0,704043 & $-0,203672$ & 0,380944 & 0,334916 \\
\hline
\end{tabular}

Fonte: elaboração dos autores, 2020.

Analisando conjuntamente os resultados do teste de correlação de Spearman e da ACP para Petrópolis, observa-se uma congruência, já que as partículas inaláveis, por apresentarem menor tamanho que os demais poluentes, são as que mais afetam a saúde humana em termos de doenças respiratórias, dada a facilidade de penetrar nos alvéolos pulmonares, bem como maior facilidade de ser transportada pelos ventos.

A hipótese acima fica evidente no resultado da PCA de Petrópolis, o qual demonstra que a variância dos dados de internações é explicada, principalmente, pelas partículas inaláveis e o dióxido de nitrogênio emitidos nas proximidades da refinaria. Considerando que esses poluentes tiveram que transpor o obstáculo orográfico (Serra do Mar), e que o setor industrial de Petrópolis é pouco desenvolvido e apresenta baixo/médio potencial poluidor, é natural que as partículas menores e mais leves se sobressaiam.

Analisando conjuntamente os resultados do teste de correlação de Spearman e da ACP para Petrópolis, observa-se uma congruência, já que as partículas inaláveis, por apresentarem menor tamanho que os demais poluentes, são as que mais afetam a saúde 
humana em termos de doenças respiratórias, dada a facilidade de penetrar nos alvéolos pulmonares, bem como maior facilidade de ser transportada pelos ventos.

A hipótese acima fica evidente no resultado da PCA de Petrópolis, o qual demonstra que a variância dos dados de internações é explicada, principalmente, pelas partículas inaláveis e o dióxido de nitrogênio emitidos nas proximidades da refinaria. Considerando que esses poluentes tiveram que transpor o obstáculo orográfico (Serra do Mar), e que o setor industrial de Petrópolis é pouco desenvolvido e apresenta baixo/médio potencial poluidor, é natural que as partículas menores e mais leves se sobressaiam.

Já para Duque de Caxias o resultado da PCA indicou que o dióxido de nitrogênio e o ozônio são os principais poluentes responsáveis pelas internações, resultado igualmente coerente dado que o monóxido de nitrogênio tem como principais fontes de contaminação os automóveis e os incineradores industriais e a partir dele são formados tanto o $\mathrm{NO}_{2}$ quanto 0 $\mathrm{O}_{3}$. Muito provavelmente trata-se do reflexo da malha viária instalada no município, com rodovias de importância nacional para, sobretudo, o escoamento de mercadorias; bem como a presença da refinaria e indústrias subsidiárias que se espalham por todo o território municipal, dada a flexibilidade da legislação de uso e ocupação do solo (OSCAR JÚNIOR, 2016).

Vale destacar que o ozônio também é formado por um processo complexo em que os principais reagentes, junto com o NO, são os compostos orgânicos voláteis (COV) que segundo Cavalcanti (2010, p. 214), “[...] são responsáveis por uma grande parcela da oxidação do $\mathrm{NO}$ a $\mathrm{NO}_{2}$ e, por conseguinte, pelo aumento da eficiência do processo de formação do ozônio". Trata-se, portanto, de um processo mais lento e secundário de formação, o que ajuda a compreender a dificuldade das técnicas estatísticas em correlacionálo aos casos de internações; porém, devido a melhor robustez da técnica, a ACP conseguiu identificá-los como fundamentais, haja vista o resultado das cargas fatoriais das primeiras componentes principais.

\section{CONSIDERAÇÕES FINAIS}

Com o crescimento urbano planejado para atender a lógica capitalista de produção do espaço, as indústrias que antes foram alocadas em áreas mais afastadas hoje compartilham espaço com população, o que traz riscos para a saúde dessas pessoas.

No período analisado a primeira grande ressalva a se fazer é sobre a violação dos valores de partículas inaláveis nos padrões primário e secundário, apresentando o ano de 2017 valores excessivos. Isso ressalta a importância de se manter o acompanhamento sobre os valores de todos os poluentes, dando maior atenção nesse caso a este parâmetro. 
Vale ressaltar que esse trabalho possui algumas limitações; a primeira se refere aos bancos de dados em geral; o de internações traz informações referentes apenas aos hospitais públicos, fazendo com que se tenha ignorado qualquer informação do serviço privado.

Outro problema dos dados coletados no DATASUS é que não possuem outras informações dos pacientes, necessárias para identificar os elementos de pré-disposição e maior vulnerabilidade a doenças respiratórias: local de moradia, histórico médico, e se é fumante, por exemplo. Tais dados, se discriminados por localização dos hospitais, também seriam de grande importância para a melhor compreensão da lógica espacial da problemática.

Ainda outro problema encontrado na obtenção de dados se refere aos valores dos poluentes atmosféricos. Devido a prováveis problemas técnicos nas estações de monitoramento, são diversos os dias e horas que não possuem dados. Por vezes, existem dados para apenas alguns poluentes. A ausência desses poluentes pode alterar os resultados para os anos estudados, como de 2017 para as partículas inaláveis; ele não está entre os que tiveram mais dias fora dos padrões estabelecidos, porém é o que aparece com valores diários ainda mais altos que o padrão.

Ademais, como já citado anteriormente, a cidade de Petrópolis carece de estações ambientais medidoras de poluição do ar e de dados meteorológicos, impedindo a comparação mais profunda e confiável entre ambos os municípios, permitindo um melhor alcance dos resultados e da problemática em tela. A discussão sobre a criação de pontos de monitoramento existe na cidade, porém até o momento não evoluiu. A grande preocupação é: em qual momento começarão a se preocupar com o monitoramento e controle ambiental?

Vale ressaltar também que além das fábricas e da possível contribuição de empreendimentos localizados em outros municípios, o número de fontes móveis vem crescendo exponencialmente em Petrópolis. De acordo com dados do DETRAN-RJ, de janeiro de 2013 a dezembro de 2017 o número de carros aumentou 18,23\% e o de motocicletas, 21,88\% (PEPE, 2018). Em uma cidade de pequeno porte, onde comércio e serviços são concentrados em uma pequena área e com um número de automóveis por habitante cada vez maior, já superando o da cidade do Rio de Janeiro, é urgente que a prefeitura invista em conscientização e implemente uma política municipal de monitoramento da qualidade do ar.

Petrópolis também é uma cidade que carece de referências sobre suas indústrias e sua urbanização. Na literatura, os dados mais recentes de industrialização remetem a 2004, e, mesmo assim, sem informações mais detalhadas como, por exemplo, de localização. Levando em consideração todas as ressalvas, os resultados apontam para uma possibilidade positiva da poluição emitida em Duque de Caxias, em especial pela REDUC, chegar até a cidade de Petrópolis, já que o poluente mais relacionado às internações são as partículas inaláveis, sendo as mesmas as maiores responsáveis por problemas de saúde e mais fáceis de serem 
transportadas. Isso abre espaço para outras discussões, como a respeito da redistribuição dos royalties do Petróleo, em que fica o questionamento de como os royalties devem ser distribuídos caso a consequência da exploração dos recursos não atinja apenas o município sede.

É preciso buscar reduzir as emissões e os efeitos da degradação da atmosfera. Cabe ao poder público obter dados, a fim de realizar uma boa gestão com ações preventivas para que haja controle dos passivos, nunca esquecendo que o problema também está diretamente relacionado com o ordenamento territorial municipal e metropolitano e o nível da qualidade de vida de sua população (FARIAS, 2013). A preocupação com os altos níveis de emissão de poluentes deve ser uma das prioridades para qualquer governo, já que além de problemas respiratórios, pode ter também como consequências possíveis alterações no clima urbano local, problemas sanitários, danos para a vegetação e impactos significativos na economia.

\section{REFERÊNCIAS}

ABREU, M. A evolução urbana do Rio de Janeiro. Rio de Janeiro: IPLANRIO: Zahar, 1987.

BECK, U. Sociedade de risco: rumo a uma outra modernidade. São Paulo: Ed. 34, 2010.

BRASIL. Ministério de Meio Ambiente. Programa Nacional de Controle de Qualidade do Ar - PRONAR. Brasília, DF: MMA, 2018. Disponível em:

http://www.mma.gov.br/estruturas/163/_arquivos/pronar_163.pdf. Acesso em: 7 nov. 2018.

BRASIL. Ministério de Meio Ambiente. Resolução CONAMA no 03/1990 de 28 de junho de 1990. Diário Oficial da República Federativa do Brasil: seção:1, Brasília, DF, p. 1539715639, 22 out. 1990.

CABRAL, L. M. da S.; LOPES, R. A. A. L. Industrialização têxtil de Petrópolis: estudo de caso sobre a companhia petropolitana de tecidos. Intervozes: Trabalho, Saúde, Cultura. Petrópolis, v. 1, n. 1, p. 6-23, maio/out. 2016.

CAVALCANTI, P. M. P. S. Modelo de gestão da qualidade do ar: abordagem preventiva e corretiva. 2010. Tese (Doutorado em Planejamento Energético) - Universidade Federal do Rio de Janeiro, Rio de Janeiro, 2010. Disponível em http://www.ppe.ufrj.br/images/publica\%C3\%A7\%C3\%B5es/doutorado/Paulina_Maria_Porto_ Silva_Cavalcanti.pdf. Acesso em: 14 mar. 2020.

DATASUS. Departamento de Informática do SUS. Morbidade hospitalar do SUS: por local de internação - Rio de Janeiro. 2018. Disponível em:

http://tabnet.datasus.gov.br/cgi/tabcgi.exe?sih/cnv/nirj.def. Acesso em: 28 nov. 2018.

DAVIDOVICH, F. R. Estado do Rio de Janeiro: o urbano metropolitano, hipóteses e questões. Geo UERJ, Rio de Janeiro, n. 21, v. 2, p. 1 - 23, 2010.

EGLER, C. A. G. Risco ambiental como critério de gestão do território. Território, Rio de Janeiro, n. 1, p. 31-41, 1996. 
Poluição do Ar e Doenças Respiratórias: estudo de correlação das emissões atmosféricas e impacto...

ENDMEMO. Chemistry applications. 2020. Disponível em: http://www.endmemo.com/. Acesso em: 7 mar. 2020.

FARIAS, H. S. Bacias Aéreas: uma proposta metodológica para o estudo da qualidade do ar em áreas influenciadas pelo relevo. Revista Brasileira de Climatologia, Curitiba, PR, ano 9, v. 12 , p. 48 - 60, jan./jul. 2013.

FREITAS, C.; BREMNER, S. A.; GOUVEIA, N.; PEREIRA, L. A. A.; SALDIVA, P. H. N. Internações e óbitos e sua relação com a poluição atmosférica em São Paulo, 1993 a 1997.

Revista Saúde Pública, São Paulo, SP, v. 38, n. 6, p. 751-757, 2004. Disponível em: http://www.scielo.br/scielo.php?pid=S0034-89102004000600001\&script=sci_abstract. Acesso em: 4 dez. 2018.

GALVANI, E.; LUCHIARI, A. Critérios para classificação de anos com regime pluviométrico normal, seco e úmido. In: ENCONTRO DE GEÓGRAFOS DA AMÉRICA LATINA, 10., 2005, São Paulo. Anais [...]. São Paulo: Departamento de Geografia, Universidade de São Paulo, 2005. p. $5701-5710$.

GREGÓRIO, L. S. Risco ambiental à saúde humana: um estudo aplicado aos efeitos da poluição atmosférica no Estado do Rio de Janeiro. 2011. Dissertação (Mestrado em Geografia) - Universidade Federal do Rio de Janeiro, Rio de Janeiro, 2011. Disponível em: http://objdig.ufrj.br/16/teses/772542.pdf. Acesso em: 27 out. 2018.

INSTITUTO ESTADUAL DO AMBIENTE - INEA. Relatório anual de qualidade do Ar. 2016. Rio de Janeiro, RJ: INEA, 2016. Disponível em:

http://www.inea.rj.gov.br/cs/groups/public/@inter_dimfis_gear/documents/document/zwew/mt mx/ edisp/inea0131852.pdf. Acesso em: 14 nov. 2018.

LYRA, W. D. S.; SILVA, E. C. D.; ARAÚJO, M. C. U. D.; FRAGOSO, W. D.; VERAS, G. Classificação periódica: um exemplo didático para ensinar análise de componentes principais. Química Nova, São Paulo, v. 33, n. 7, 1594-1597, 2010.

MARAFON, G. J. Regiões de Governo do Estado do Rio de Janeiro: uma contribuição geográfica. Rio de Janeiro: Gramma, 2005.

MELO, F. P. Risco ambiental e ordenamento do território em Garanhus-PE. 2016. Tese (Doutorado em Geografia) - Universidade Federal do Sergipe, Sergipe, 2016. Disponível em: https://ri.ufs.br/handle/riufs/5464. Acesso em: 19 fev. 2020.

MONTEIRO, C. A. F. M. Teoria e clima urbano. São Paulo: IGEOG/USP, 1976.

NUNES, L. H. Compreensões e ações frente aos padrões espaciais e temporais de riscos e desastres. Revista Territorium, Lisboa, n. 16, p. 179-189, 2009.

OSCAR JÚNIOR, A. C. S. Avaliação do subcanal físico-químico em Duque de Caxias (RJ): a influência das políticas municipais de ordenamento territorial no clima urbano. RDG: Revista do Departamento de Geografia, São Paulo, SP, p. 24-38, 2016. Volume especial. Disponível em: https://www.revistas.usp.br/rdg/article/download/117539/118962/. Acesso em: 15 dez. 2018.

PEPE, P. (org.). Anuário estatístico de 2018. Coordenadoria de estatística e acidentologia. 4. ed. Rio de Janeiro: DETRAN, 2018. Edição independente. Disponível em:

http://www.detran.rj.gov.br/_include/geral/anuario_estatistico_detran_rj_2018.pdf. Acesso em: 12 mar. 2020. 
PETROBRAS. Refinaria Duque de Caxias (Reduc). Disponível em:

https://petrobras.com.br/pt/nossas-atividades/principais-operacoes/refinarias/refinaria-duquede-caxias-reduc.htm. Acesso em: 7 mar. 2020.

SALDIVA, P. Vida urbana e saúde. São Paulo: Contexto, 2018.

Recebido: setembro de 2019. Aceito: março de 2020. 